\title{
A latex particle precipitation test in the diagnosis of thyroid disease
}

\author{
J. R. PHILP, D. M. WEIR, A. E. STUART, AND W. J. IRVINE \\ From the Departments of Bacteriology, Pathology, and Therapeutics, \\ University of Edinburgh
}

SYNOPSIS The method of latex particle precipitation has been applied to the detection of circulating $\vec{\tau}$ antibody to a crude extract of thyroid. The sensitivity of the method is intermediate between that of the agar diffusion and the tanned cell haemagglutination techniques. If only the grosser degree of latex precipitation are taken as being significant, the method would appear to be of equal value as the agar diffusion test in the diagnosis of lymphadenoid goitre.

The use of inert particles such as latex, bentonite, and collodion has provided an additional simple method for detecting circulating antibody. The particles are coated with the appropriate antigen and the presence of the corresponding antibody is indicated by agglutination or precipitation of the particles.

Polystyrene latex particles have been used in this way by Singer and Plotz $(1956,1958)$ and Olsen and Rantz (1958) for the detection of rheumatoid factor and more recently by Christian, MendezBryan, and Larson (1958) and Fessel (1959) for the detection of LE factor, and by Kelen and Labzoffsky (1960) for the detection of antibodies to Leptospira.

The purpose of this paper is to evaluate the usefulness of antigen-coated latex particles in the detection of thyroid antibodies and to compare this method with the established procedures of tanned cell haemagglutination and agar gel diffusion.

\section{LABORATORY METHODS}

SALINE EXTRACT OF THYROID AND LIVER Human thyroid tissue was obtained at thyroidectomy or from a fresh cadaver. Liver tissue was likewise obtained at an early necropsy. The tissues were frozen immediately in a vacuum flask surrounded by an alcohol and solid carbon dioxide mixture. They were then cut into small pieces and homogenised in the cold for two minutes at high speed in an M.S.E. homogeniser with an equal volume of saline. After the addition of a further volume of saline the homogenate was frozen and thawed three times and left to extract overnight at $4^{\circ} \mathrm{C}$. The coarse sediment was removed by centrifugation for five minutes at 2,000 r.p.m.

Received for publication 29 August 1961. in an M.S.E. major refrigerated centrifuge, and the supernatant centrifuged at $59,310 \mathrm{~g}$ in a preparative Spinco. The supernatant was used as the antigen. It was stored at $-20^{\circ} \mathrm{C}$.

POLYSTYRENE LATEX A suspension of Difco latex pa旅 ticles, $0.81 \mu$ in diameter, was used as supplied bo Baird \& Tatlock, Ltd., London.

GLYCINE BUfFER Glycine in $1 \% \mathrm{NaCl} 0.1 \mathrm{M}$, was a $\overrightarrow{\vec{G}}$ justed to $p \mathrm{H} 8.2$ with a solution containing $2.5 \mathrm{~m}$. $\mathrm{N} / 1 \mathrm{NaOH} / \mathrm{litre}$ and with $10 \%$ citric acid. This $p \mathrm{H}$ wa found to give optimal precipitation of the antigen-coated latex particles.

LATEX TEST After preliminary studies using dilutions of antigen (thyroid extract) up to $1: 1,000$ it was found necessary to use dilutions of 1 in 5,1 in 10 , and 1 in 25 Maximal precipitation for a given serum was found tê take place with any one of these three dilutions in 29 unpredictable manner. Dilutions of antigen higher than 1 in 25 in no case enhanced the degree of precipitatio

The antibody in the form of test serum was used in a undiluted state, since dilution of the serum did not increase the degree of precipitation. The sera had beeng stored at $-20^{\circ} \mathrm{C}$. for two to three years and had bee inactivated for previous diagnostic tests. Further heating was not carried out.

Dilutions of the latex suspension of 1 in 10 and 1 in 20 were made in the glycine buffer. The 1 in 10 latex dilutiof was used to prepare the stock suspension of antige coated latex particles by mixing with an equal volume of each of the three antigen dilutions. The mixtures we then shaken and left on the bench for $\mathbf{3 0}$ minutes to allow adsorption of the antigen to take place. With the addition of merthiolate to 1 in 10,000 these mixtures were stable at $4^{\circ} \mathrm{C}$. for at least one month. Two drops of the antigerlatex suspension at each dilution of the antigen wese 
then transferred to 3 in. $\times \frac{1}{2}$ in. tubes and two drops of undiluted serum were added to each. After shaking, the mixture was drawn up into capillary tubes which were placed in plasticine racks. The 1 in 20 dilution of uncoated latex suspension was used to set up a control test for each test serum.

The capillary tubes were kept on the bench and examined after three, 24 , and 48 hours for precipitation. No further precipitation occurred after 48 hours. Incubating at fixed temperatures in the range of $4^{\circ}$ to $56^{\circ} \mathrm{C}$. was not found to enhance the degree of precipitation. The degrees of precipitation were designated by the digits 0 , $1,2,3$, and 4 , according to the length of the fragmented column of precipitated particles, 0 signifying no precipitation and 4 maximal precipitation, with 1,2 , and 3 intermediate degrees respectively (Fig. 1). The degree of precipitation was apparent in the majority of cases overnight but was finally read at 48 hours. The strongest degree of precipitation observed in any of the three tubes was taken as the final reading.

GEL DIFFUSION TEST The agar double diffusion technique (Oudin, 1948) was used as modified by Oakley and Fulthorpe (1953).

TANNED RED CELL TEST The test using thyroglobulincoated sheep red cells was that used by Roitt and Doniach (1958) after Rose and Witebsky (1956). Purified thyroglobulin prepared after the method of Derrien, Michel, and Roche (1948) was used.

\section{CLINICAL MATERIAL}

The sera were selected from specimens which had been kept after examination for thyroid antibodies for diagnostic purposes (Irvine, 1960a). No attempt is made in the present study to determine the incidence of positive immunological tests in unselected thyroid patients. Each serum was given a number and all tests were carried out in ignorance of the diagnosis and the results of other tests. The following sera were used:-

Fifty-three sera from 32 histologically proven cases of lymphadenoid goitre, 21 of which were obtained from 10 patients who, at the time, had had no surgical interference or only biopsy, and the remaining 32 sera were obtained from 22 patients who had had a partial or hemithyroidectomy, anything from a few days to 10 years previously.

Fifty-eight sera were from 51 cases of lymphadenoid goitre diagnosed clinically without histological proof.

Twenty-two sera were obtained from 17 cases of spontaneous adult hypothyroidism.

Thirty-six sera were from 31 patients with simple goitre, 20 of whom had subsequent histological proof.

Twenty sera were from 16 cases of carcinoma of the thyroid, all histologically proven but sera obtained either before or after treatment.

Twenty-nine sera were from 22 cases of thyrotoxicosis.

Two sera were from two cretinous children.

Four sera were from four patients with subacute (de Quervain's) thyroiditis. In two cases histology was available.

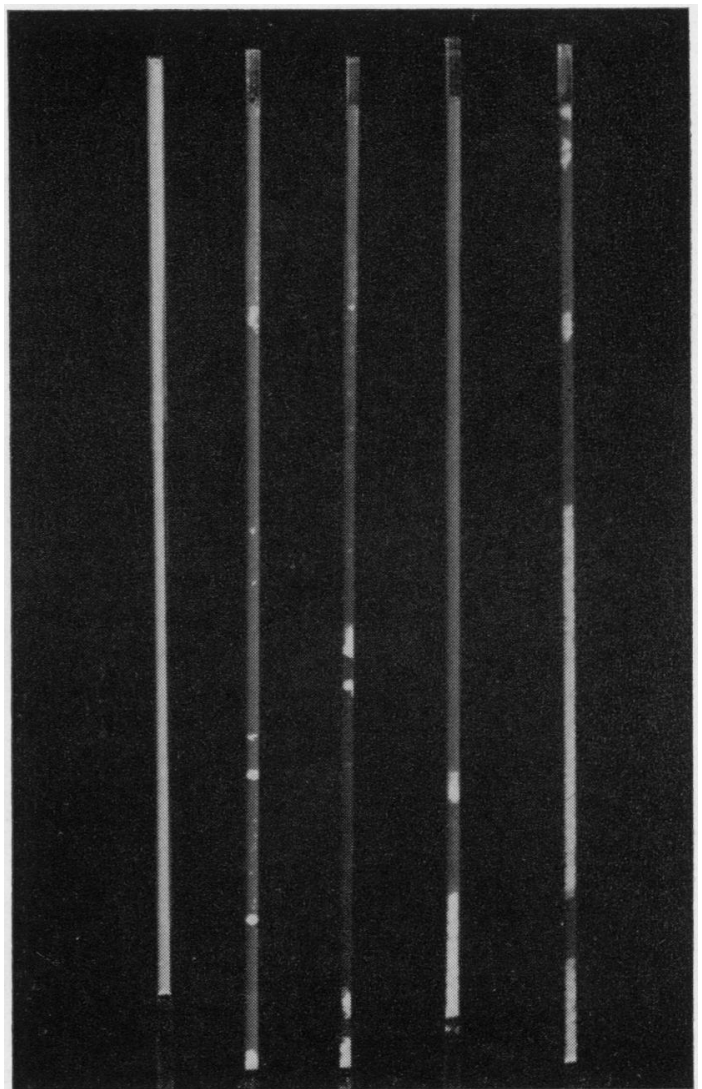

FIG. 1. The five capillary tubes illustrated are selected from tests described in the text using various negative and positive sera at the different antigen dilutions. Reading from left to right the tubes have been arranged to show degrees of precipitation graded as $0,1,2,3$, and 4. The degree of precipitation is assessed according to the length of the fractionated column of precipitated particles. To the naked eye the consistency of the latex is that of a suspension in tube 0 and is clearly floccular in tube 4, although this is difficult to illustrate in a photograph.

Fifty-one sera were from 51 cases of rheumatoid arthritis. All these sera had strongly positive Rose-Waaler tests.

Six sera were from six cases of systemic lupus erythematosus (S.L.E.).

Seventy sera were from 70 healthy antenatal patients (normal controls).

\section{RESULTS}

Table I shows the distribution of $0,1,2,3$, and 4 reactions in the latex capillary test. It will be seen that while none of the 70 normal sera precipitated the coated particles some degree of precipitation 
TABLE I

DISTRIBUTION OF REACTIONS IN LATEX CAPILLARY TEST

\begin{tabular}{lr} 
Diagnosis & No. of \\
& \\
\hline Lymphadenoid goitre (clinically \pm histology) & 111 \\
Spontaneous hypothyroidism & 22 \\
Simple goitre & 36 \\
Carcinoma thyroid & 20 \\
Thyrotoxicosis & 29 \\
Cretins & 2 \\
Subacute thyroiditis & 4 \\
Rheumatoid arthritis & 51 \\
S.L.E. & 6 \\
Normal (ante-natal) & 70 \\
Totals & 351
\end{tabular}

TABLE II

SERA GIVING POSITIVE AGAR DIFFUSION TESTS

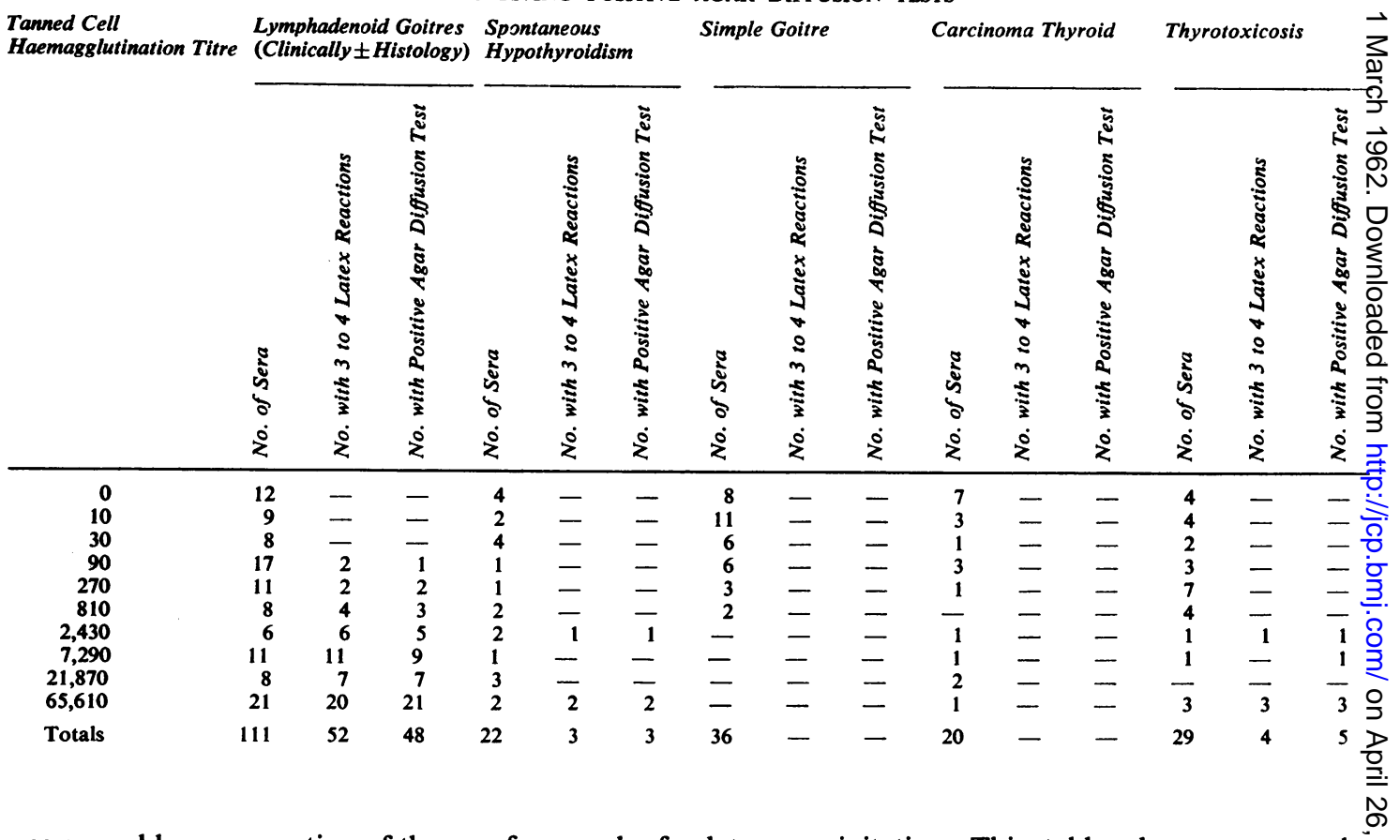

was caused by a proportion of the sera from each of the other groups studied. It is also apparent that the highest proportion of sera giving three and four reactions occur in the lymphadenoid goitre group while lesser degrees of precipitation (0-2) are encountered in other types of thyroid diseases.

Table II shows the number of sera in each group of patients that gave a positive agar diffusion test for thyroglobulin antibody. They correspond closely with the number of sera giving three and four latex reactions. Five sera gave a 3 to 4 latex reaction, but a negative agar diffusion test, while two sera gave a positive agar diffusion test but did not give 3 or 4 latex precipitation. This table also compares then latex and agar diffusion tests with the tanned celf haemagglutination test using thyroglobulin-coated sheep red cells. It will be seen that the positive agat diffusion test and the $3+4$ latex reactions are dis 0 tributed towards the higher end of the tanned celf? haemagglutination titre scale. The tanned cell haem:agglutination titres are widely distributed in thyroid disease, and it is of interest that three cases of carcinoma of the thyroid gave a high titre and yet? both the agar diffusion and the latex capillary tests ${ }^{\circ}$ were negative. It is also of interest that two sera frome one patient with histological proof and two sera fromb 
TABLE III

LYMPHADENOID GOITRE HISTOLOGICALLY PROVEN

Tanned Cell

Haemagglutination Titre
Biopsy Only or before Thyroidectomy

\begin{tabular}{lll}
\hline Patients & $\begin{array}{l}3 \text { to } 4 \text { Latex } \\
\text { Reactions }\end{array}$ & $\begin{array}{l}\text { Positive Agar } \\
\text { Diffusion Test }\end{array}$
\end{tabular}

Up to 10 years Post-thyroidectomy

\begin{tabular}{lll}
\hline Patients & $\begin{array}{l}3 \text { to } 4 \text { Latex } \\
\text { Reactions }\end{array}$ & $\begin{array}{l}\text { Positive Agar } \\
\text { Diffusion Test }\end{array}$
\end{tabular}

\begin{tabular}{|c|c|c|c|c|c|c|}
\hline 0 & 1 & - & - & 6 & - & - \\
\hline 10 & 1 & - & - & 3 & - & - \\
\hline $\begin{array}{l}30 \\
90\end{array}$ & $\overline{1}$ & $\bar{z}$ & I & $\overline{4}$ & $=$ & $\bar{z}$ \\
\hline 270 & 1 & $=$ & - & 2 & $=$ & $\overline{-}$ \\
\hline 810 & 1 & 1 & 1 & 1 & - & - \\
\hline 2,430 & 1 & 1 & 1 & 1 & 1 & - \\
\hline $\mathbf{7 , 2 9 0}$ & 1 & 1 & 1 & 1 & 1 & 1 \\
\hline 21,870 & 3 & 3 & 3 & 4 & 3 & 4 \\
\hline Totals & 10 & 6 & 6 & 22 & 5 & 5 \\
\hline
\end{tabular}

two cases diagnosed clinically as having lymphadenoid goitre gave tanned cell haemagglutination titres of 270 or less, but still gave positive 3 and 4 latex reactions.

A small proportion of sera from patients with rheumatoid arthritis and S.L.E. precipitated thyroglobulin-coated latex particles (1, 2, and 3 reactions), but such sera can be distinguished by the fact that they will also cause precipitation of the uncoated latex control particles or of latex particles coated with human liver antigen. Such non-specific precipitation did not occur with any of the 232 thyroid sera in spite of the fact that the incidence of rheumatoid arthritis and of lupus erythematosus antinuclear factor is known to be raised in lymphadenoid goitre (Buchanan, Crooks, Alexander, Koutras, Wayne, and Gray, 1961; Weir, Holborow, and Johnson, 1961). These results, together with the absence of any degree of precipitation by the 70 normal sera, indicate the specificity of the test for thyroid antibodies.

The main clinical interest attached to the detection of thyroid antibodies is in the diagnosis of lymphadenoid goitre. The results in this disease are shown in Table III, where the patients are divided into two series. First, a small series of 10 patients from whom sera were obtained before thyroidectomy and, secondly, a larger series of 22 patients in whom serological tests were carried out at various intervals after surgery. It is again seen that there is a close parallel between the agar diffusion test and the latex method.

\section{DISCUSSION AND CONCLUSIONS}

A method of using latex particles for the detection of thyroglobulin antibody is described which is both extremely cheap and easy to perform. The time of reading the test is shorter than with the agar diffusion method, in which eight days should be allowed to elapse before pronouncing the result to be negative. The sensitivity of the capillary latex method for the detection of thyroglobulin antibodies is appreciably greater than that of the agar diffusion test, but markedly less than the tanned cell haemagglutination test. However, when only three and four reactions are taken into account as being significant the sensitivity of the method and its specificity within the range of thyroid diseases make the capillary latex test and the agar diffusion test of equal diagnostic value in lymphadenoid goitre.

No figures can as yet be given to indicate the true incidence of positive capillary latex tests in the various thyroid disorders. In the case of lymphadenoid goitre this would require the serological test to be done before treatment in patients in whom the diagnosis was subsequently established on the basis of adequate histology. As far as we are aware no such series of patients has yet been published even for the agar diffusion test. In the present series the incidence of positive agar diffusion tests of $60 \%$ in those lymphadenoid goitre patients who had not had thyroidectomy and of some $25 \%$ in those patients in whom thyroidectomy had been performed up to 10 years previously is consistent with current views. A similar incidence is found with the capillary latex test when 3 to 4 reactions are used.

The main objections to the capillary latex technique is the interpretation of what constitutes a grade 1 or 2 precipitation as opposed to grades 3 or 4 . With experience of the method this difficulty is readily overcome and consistent results obtained. An improved method of grading might be to measure the total length of the discrete fragments in a positive column (see Fig. 1). Failure to grade the test results in loss of diagnostic specificity for lymphadenoid goitre. The same problem arises with the tanned red cell technique where there is uncertainty in selecting an arbitrary titre of diagnostic value in lymphadenoid goitre. On the other hand the agar diffusion test in the majority of cases gives a clear positive or negative result although a weak reaction can cause considerable difficulty. 
It is necessary to carry out control tests using uncoated latex particles to exclude the possibility of obtaining false positive results with rheumatoid or systemic lupus erythematosus sera.

In conclusion, while the tanned cell haemagglutination technique (Roitt and Doniach, 1958) and the complement-fixation test (Trotter, Belyavin, and Waddams, 1957) remain as the techniques for the sensitive and quantitative measurement of circulating thyroid antibodies, the capillary latex method may prove to be of value as a rapid screening test in cases suspected clinically of having lymphadenoid goitre, possessing as it does the combined virtues of cheapness, ease of performance and readability, and a specificity for this disease equal to that of the agar diffusion test. Diagnostically, however, the capillary latex method is likely to have the same limitations as the agar diffusion test because it will fail to reveal those patients with Hashimoto disease with negative or insignificant titres of thyroglobulin antibody but high titres of circulating antibody directed against intracellular antigen detected by the method of complement fixation (Trotter et al., 1957) or cytotoxicity (Irvine, 1960b, 1961a, 1961b). Conversely the complement-fixation test per se would not detect those patients who only possess antibody to thyroglobulin. It would therefore appear that a combination of these two types of test is required for diagnostic purposes.

Our thanks are due to Professor Robert Cruickshank for his interest in the development of the capillary latex test.
We are also indebted to Professor Sir Derrick Dunlop and Dr. J. S. Robson for allowing us to study the patients, and to the many other clinicians (in particula? Dr. W. R. M. Alexander of the Rheumatic Unit at the Northern General Hospital) for kindly sending us ser:

J. R. P. and W. J. I. wish to acknowledge grants froif the Medical Research Council and A.E.S. from tt Secretary of State for Scotland through the Advisory Committee for Medical Research.

\section{REFERENCES}

Buchanan, W. W., Crooks, J., Alexander, W. D., Koutras, D.

Wayne, E. J., and Gray, K. G. (1961). Lancet, 1, 245.
Christian, C. L., Mendez-Bryan, R., and Larson, D. L. (1958g Proc. Soc. exp. Biol. (N.Y.), 98, 820.

Derrien, Y., Michel, R., and Roche, J. (1948). Biochem. biophys. Actets 2, 454.

Fessel, W. J. (1959). Ann. rheum. Dis., 18, 255.

Irvine, W. J. (1960a). The Diagnosis of Lymphadenoid Goitre. Lew Cameron Post-graduate Prize Essay. Edinburgh University. -

- (1960b). Scot. med. J., 5, 511.

- (1961a). Advances in Thyroid Research. Trans. 4th int. Goit Conference, London, 1960, p. 154 (ed. R. Pitt-Rivers Pergamon Press, Oxford.

- (1961b). Clark Fellowship Lecture. Edinburgh. To be published A. E., and Labzoffsky, N. A. (1960). Canad. J. Microbiol., 6ु

Oakley, C. L., and Fulthorpe, A. J. (1953). J. Path. Bact.. 65, 49. Olsen, C. R., and Rantz, L. A. (1958). Arthr. and Rheum.. 1, 54. Oudin, J. (1948). Ann. Inst. Pasteur, 75, 30.

Roitt, I. M., and Doniach, D. (1958). Lancet, 2, 1027.

Rose, N. R., and Witebsky, E. (1956). J. Immunol., 76, 417.

Singer, J. M., and Plotz, C. M. (1956). Amer. J. Med., 21. 888. (1958). Arthr. and Rheum., 1, 142.

Trotter, W. R., Belyavin, G., and Waddams, A. (1957). Pros. roy. So Med., 50, 961.

Weir, D. M., Holborow, E. J., and Johnson. G. D. (1961). Brit. me

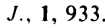

